\title{
Contribuição para um catálogo bibliográfico dos antigos alunos da Faculdade de Direito de São Paulo
}

3. ${ }^{a}$ Parte, compreendendo os bachareis formados de 1880 a 1883

\section{0}

ANTONIO LUIZ DOS SANTOS WERNECK

Imunidades dos Ministros - (Tése) Tip. Jorge Seckler \& Cia. - São Paulo, 1881 - 1 folh.

\section{JOSE' JOAQUIM CARDOSO DE MELLO JUNIOR}

Rescisão por lesão enorme no caso de venda de direitos hereditarios - Ap. Civ. 1953 - Capital Tip. da Cia. Industrial - Sāo Paulo, $1892-1$ folh.

Fideicommisso - Ap. civ. da Capital - Tip. Casa Garraux -São Paulo, 1893 - 1 folh.

Contas impugnadas de sindicos em liquidação forçada-Ap. Civ. 260 - Capital - Tip. da Cia. Industrial, São Paulo 1893, 1 folh.

Anulação de inventario - Ap. Civ. - Capital - Tip. da Cia. Industrial, São Paulo 1894, 1 folh.

Manutenção de posse - Ap. civ. da Capital - Tip. da Comp. Industrial - São Paulo, 1895 - 1 folh.

Manutenção de posse - Ap. civ. 894 de Itatiba - Espindola \& Cia. - São Paulo, 1896 - 1 folb. 
Orientação de rumos - Ap. civ. de S. Pedro - Tip. da Cia. Industrial - S. Paulo, 1896 - 1 folh.

Partilha de rendimentos de imoveis comuns - Ap. civ. da Capital - Tip. da Cia. Industrial -- S. Paulo, 1896 - 1 folh.

Manutenção de posse - Ap civ. 1273 de Piracicaba - Tip. da Comp. Industrial - São Paulo, 1897 - 1 folh.

Como se constituem as servidões - Embargos n. 911 - Faxina - Tip. da Cia. Industrial — S. Paulo, $1897 \ldots 1$ folh.

Responsabilidade civil do caçador por danos causados a plantações alheias - Ap. civ. - Balataes - Tip. Cia. Industrial - São Paulo, 1897 -- 1 folh.

Rescisão de contrato de empreitada - Ap Civ. 1361 - Campinas - Gerke \& Cia. São Paulo, 1898, 1 folh.

Ação cambial - Agravo comercial n. 1811 - Capital - Gerke \& Cia. - S. Paulo, $1899-1$ folh.

Execução de sentença proferida em ação "finium regundorum" Agr. civ. 1877 - Gerke \& Cia. - S. Paulo, 1889 - 1 folb.

Partilha de rendimentos de bens de espolio entre herdeiros e legatarios de cousa certa. - Ap. Civ. 2068 - Rio Claro - Gerke \& Cia. - S. Paulo, 1889 - 1 folh.

Empreitada rescindida. Lucros cessantes. Liquidação de sentença - Campinas - Gerke \& Cia. - S. Paulo, $1900-1$ folh.

Ação recisoria de julgado - Embargos 1782 - Capital - Gerke \& Cia. - S. Paulo, $1900-1$ folh.

Ação ordinaria de cobrança -- Ap Civ. 2558 - Itatiba - Gerke \& Cia. - S. Paulo, $1900-1$ folb.

Requisitos da ação "judicali" ou "in factum" - Ap. civ. 2599 - Capital -.. Gerke \& Cia. - S. Paulo, 1900 - 1 folh.

Avaliação de lucros cessantes pelo facto de recisão de contrato de empreitada - Agr. civ. 2642 - Campinas - Gerke \& Cia. S. Paulo, $1900-1$ folh.

Execução de sentença em ação de demarcação - Embargos 2034 - S. Pedro - Gerke \& Cia. - S. Paulo, 1901 - 1 folh.

Ação reivindicatoria - Ap. civ. 2584 - Capital - Gerke \& Cia. - S. Paulo, $1901-1$ folh.

Requisitos indispensaveis para obtenção de sequestro - Ap. civ. 2836 - Capital - Gerke \& Cia. - S. Paulo, 1901 - 1 folh.

Partilha de rendimentos de bens do espolio entre herdeiros $e$ legatarios de cousa certa - Embargos civeis 2068 - Rio Claro Tip. Salesiana - S. Paulo, $1902-1$ folh.

Morto o fideicomissario antes do fiduciario, consolida-se o dominio na pessoa deste - Embargos 2811 - Capital - Gerke \& Cia. - S. Paulo, 1902 - 1 folh. 
Contrato social - Clausula permitindo exclusão de socios Ap. civ. 3287 - Brotas - Gerke \& Cia. - S. Paulo, 1902 - 1 folh.

Ação ordinaria para haver indenização de prejuizos resultantes de fatos ilicitos - Embargos civeis 3300 - Dois Corregos Tip. Salesiana - S. Paulo, $1902-1$ folh.

Restituição de importancia paga por titulos falsos -- Ap. civ. 3345 - Capital - Tip. Salesiana - S. Paulo, 1903 - 1 folh.

Culpa contratual - Ap. civ. 4028 - Agudos - Tip. Salesiana - S. Paulo, 1904 - 1 folh.

Registo de hipoteca - Ap. civ. 3992 - Dois Corregos - Tip. Salesiana - S. Paulo, 1906 - 1 folh.

Prestação de contas de tutela - Hipoteca convencional - Ap. civ. 4412 - Araraquara - Tip. Salesiana - S. Paulo, 1906 - 1 folb.

A confissão e sua indivisibilidade - Embargos 4765 - Capital - Espindola \& Cia. - S. Paulo, 1907 - 1 folh.

Nulidade de constituição de sociedade anonima - Ap. 4989 -Capital - Tip. Falcone, São Paulo, 1907, 1 folh.

Carta - conta de venda, de comissario e lavrador, não é titulo liquido e certo - Agravo Comercial 5023 - Santos - Siqueira \& Cia., São Paulo, 1908, 1 folh.

A autorização para venda de bens de interdito pode ser concedida pelo Juiz de Paz no exercicio da vara de Juiz de Direito - Embargos 4869 - Amparo - Siqueira \& Cia., São Paulo 1908, 1 folh.

Nulidade da incorporação do Banco União de S. Paulo - Embargos civeis 4989 - Capital - Siqueira \& Cia. - S. Paulo, 1908 -- 1 folh.

Questão de mandato - Embargos 5719 - Capital - (Em col. com Cardozo de Mello Neto) - Duprat \& Cia. São Paulo, 1911 1 folh.

Ação recisoria - Ap. civ. 7813 - Jaboticabal - (Em col. com Cardoso de Mello Netto) - Duprat \& Cira. - S. Paulo, 1915 - 1 folh.

Ação de reivindicação - Embargos 7556 - Sertãozinho (Idem) - Duprat \& Cia. - S. Paulo, 1916 - 1 folh.

Concurso de preferencia - Ap. 8322 - Capital (Idem) - Casa Duprat - S. Paulo, 1916 - 1 folh.

Desapropriação por utilidade publica - Ap. Civ. 9028 - Tietê (Idem) - Seç̧ão de Obras do "Estado de São Paulo" São Paulo, 1919, 1 folh. 
Ação de desquite - Conceito de "injuria grave" - Embargos 10.245 - (Idem) - Casa Duprat, São Paulo, 1920, 1 folh.

Indenização de dano resultante de fatos ilicitos - Ap. civ. 9980 - Capital - Casa Duprat - S. Paulo, 1920 - 1 folh.

A venda de uma empresa Telefônica constitue transmissão de bens muveis - Embargos 10.371 - Capital (Idem) - Casa Duprat, São Paulo 1921, 1 folh.

Improcedencia dos embargos a penhora fundados em suposta inalienabilidade do imovel penhorado - Embargos 10817 - Jaboticabal - (Em col. com Cardoso de Mello Netto) - Casa Duprat S. Paulo, $1922-1$ folb.

Desquite - Embargos n..$^{\circ} 45$ - Capital - Casa Duprat - São Paulo, 1920 - 1 folb. - (Em colaboração com J. J. Cardozo de Mello Netto).

Transmissão de bens imoveis - Embargos 10.371, da Capital -Casa Duprat - São Paulo, 1921 — 1 folb. - (Em colaboração com J. J. Cardozo de Mello Neto).

Distribuição de responsabilidade entre um novo municipio $e$ o antigo prejudicado pelo desmembramento daquele - Embargos 10.592 - Casa Duprat - São Paulo, 1922 - 1 folh. - (Em colaboração com J. J. Cardozo de Mello Neto e José Rodrigues Tucunduva).

Enfiteuse - Embargos 12.006, de Santos -- Secção de Obras do "Estado de São Paulo" -- São Paulo, 1923 - 1 folh. - (Em colaboração com J. J. Cardozo de Mello Neto).

Sociedade de seguro mutuo - Diversas questóes - Embargos Civeis 11.065 - Capital (Idem) - Secção de Obras do "Estado de São Paulo", São Paulo 1923, 1 folh.

Disputa de preferencias, em ação ordinaria. - Ap. Civ. 12.466 - Santos (Idem) - Secção de Obras do "Estado de São Paulo" São Paulo, 1923, 1 folh.

Ação reivindicatoria - Defesa fundada na ausencia de provas do domicilio da A. sôbre o terreno reivindicado que a Ré teria adquiriclo pelo usucapião - Ap. Civ. 14.155 - Capital (Idem) - Secção de Obras do "Estado de São Paulo", São Paulo, 1925, 1 folh.

Indenização - Embargos 13.213, de Santos - Secção de Obras do "Estado de São Paulo" — São Paulo, 1925 - (Em colaboração com J. J. Cardozo de Mello Neto).

Queixa crime por injurias impressas irrogadas á memoria do Cons. Rodrigues Alves - (Em col. com Cardoso de Mello Netto) Ap. Crime 9.423 - Capital - Casa Garraux s|d. - 1 folh.

Contrato enfiteutico rege-se pela lei do tempo do contrato Embargos civeis 12.006 - Santos - (Idem) - Secção de Obras do "Estado de S. Paulo" -.. São Paulo, 1923 - 1 folb. 
Ação "communi dividundo" - Ap. civ. 13991 - S. Manuel (Idem e Luiz Nazareno T. de Assumpção) - Sec. de Obras do "Estado de S. Paulo" - S. Paulo, $192 \overline{5}-1$ folh.

Ação de reivindicação - Embargos 14.155 - Capital - (Em col. com J. J. Cardozo de Mello Netto) - Sec. de Obras do "Estado de Săo Paulo" -- S. Paulo, 1927 - 1 folb.

Ação de nulidade de partilha em inventario - Ap. civ. 18537 - Capital - (Idem) - Empr. Graf. "Revista dos Tribunais" S. Paulo, $1930-1$ folh.

Apelação Civel 20453 - Capital -- (Idem) - Empr. Graf. "Revista dos Tribunais" — S. Paulo, 1933 _- 1 folh.

JOSE' DA SILVA VERGUEIRO

Ação ordinaria - Razões finais dos autores J. F. de Lacerda \& Cia. - União Tipografica - Santos, 1887 - 1 folh.

Memorial de agravo - União Tipografica - Santos, 1888 - 1 folb.

Agravo comercial, de Santos - Tip. do "Diario Popular" -. São Paulo, $1888-1$ folb.

Apelação comercial, de Santos - União Tipografica - Santos. $1888-1$ folh.

Questão de dissolução social - Apelação 1665 - Razões finais - - União Tipografica - Santos, 1889 - 2 folhs.

Ação de Manutenção de posse - Apelação civel - Tip. da Cia. Industrial de São Paulo - São Paulo, 1890 - 1 folh.

Agravo civel - Tip. da Cia. Industrial de São Paulo - São Paulo, 1892 - 1 folh.

\section{WENCESLAU ESCOBAR} vol.

O Gabinete 5 de Janeiro - S|editor - São Paulo, 1880 - 1

Doação ante-nupcial - In "Revista Juridica" de Porto Alegre Ano 1.' - N.' 1 - pag. 18.

Escrito particular de compra e vendas de bens de raiz, excedente de 800 s anterior a lei $n^{\circ} 840$ de 15 de Setembro de 1855 , tem valor juridico? - In "Revista Juridica" de Porto Alegre ano 1., n. 2 , pag. 146.

\section{1}

\section{ARTSTIDES DE ARAUJO MAIA}

Homestead - Tip. Brasil - Rio de Janeiro, 1896 - 1 vol.

Recordações - Imprensa Oficial de Minas Gerais - Belo Horizonte, $1902-1$ vol. 
Interpretação do art. 562 do Reg. Comercial n.' 737, de 25 de Novembro de 1850 - in - "O Direito" -- vol. 27 - pag. 337.

\section{ALGUSTO DE SIQUEIRA CARDOSO}

Notas genealogicas sôbre os ascendentes e descendentes de Pedro Taques - in - "Revista do Instituto Historico e Geografico de São Paulo" - Vol. 10 - pag., 39.

Alguns apontamentos genealogicos sôbre os ascendentes dos Malta Cardoso - in - "Revista do Instituto Historico e Geografico de São Paulo" - Vol. 19 - pag. 43.

\section{HERMENEGILDO MILITÃO DE ALMEIDA}

Estudo de algumas questôes constitucionais - Tip. Cruzeiro Rio de Jaeniro, 1880 - 1 vol.

Sôbre a propriedade (Tése) - Tip. Industrial - Recife. 1883 .... 1 folh.

A existencia $e$ o progresso da propriedade contribuem ou não para aumentar a desigualdade das condições? - in - "O Direito" -.. vol. 32 - pag. 5.

A prorogação do prazo para o pagamento exonera o fiador? - in - "O Direito" - vol. 28 - pag. 517.

$O$ pai é obrigado a dotar a filha emancipada? - in "O Direito" vol. 29 - pag. 481.

Em falta de irmãos do defunto, sucedem-lhe "in capita" ou "in stirpes" os sobrinhos? - in - "O Direito" - vol. 28 - pag. 172.

Quando as assembléas provinciais procedem como tribunais de justiça, estão sujeitas ás leis que regulam a forma do processo perante os tribunais - in - "O Direito" - vol. 24 - pag. 553.

\section{JOÃO BRAZ DE OLIVEIRA ARRUDA}

Honorarios medicos - Apelação de Campinas -- Vanorden \& Cia. - São Paulo, 1894 - 1 folh.

Cessão de bens - Agravo, de Amparo - Tip. Industrial de São Paulo - São Paulo, 1895 - 1 folh.

Ação ordinaria cível, Ribeirâa Preto - Tip. Carlos Gerke \& Cia. - São Paulo, 1898 - 1 folh.

Discurso proferido no Tribunal do Juri de Campinas em favor dos réus acusados de cumplicidade de roubo. -- Tip. Carlos Gerke \& Cia. - São Paulo, 1898 - 1 folh.

Agravo de instrumento 2520, de Ribeirão Preto -- Tip. da Industrial de São Paulo ... São Paulo, 1900 _.. 1 folh.

Agravo 2575 de Ribeirão Preto - Tip. da Industrial de São Paulo -- São Paulo, 1901 - 1 folh. 
o Direito Romano e o seu metodo - Tip. Andrade \& Mello São Paulo, 1903 - 1 vol.

Apelaşão civel 4005, de Ribeirão Preto - Escola Tipografica Salesiana - São Paulo, 1904 - 1 folh.

Defesa crime - Ribeirão Preto - Casa Beschizza - Ribeirão Preto, 1904.

Recurso crime - Espindola, Siqueira \& Cia. -- São Paulo, 1904 - 1 folh.

Agravo 3732, de Ribeirão Preto - Espinclola, Siqueira \& Cia. .. São Paulo, 1904 - 1 folb.

A pelação n." 3950, de Ribeirão Preto - Espindola, Siqueira \& Cia. - São Paulo, 1904 - 1 folh.

Embargos 3950 - Ribeirão Preto - (Em colaboração com F. Vergueiro Steidel) - Espindola, Siqueira \& Cia. - 1904 - 1 folh.

Ação decendiaria - Agravo de instrumento - Tip. da Casa Beschizza - Ribeirão Preto, 1905 - 1 folh.

Falencia fraudulenta - Duprat \& Cia. - São Paulo, 1905 1 folh.

Apelação n..$^{\circ}$ 5077, de Ribeirão Preto - Escolas Profissionais Salesianas - São Paulo, 1907 - 1 folb.

Apelação n: 4928 - Ribeirão Preto - Escolas Profissionais Salesianas - São Paulo, 1907 - 1 folh.

Preleções de Filosufia do Direito - - São Paulo, sled. - 1908 1 vol.

Resumo das lições de Direilo Criminal - - Tip. do Globo - São Paulo, $1009-1$ vol.

Apelação 6.673, da Capital -- (Em colaboração com Adolfo dos Santos Ribeiro) - Rotschild \& Cia. - São Paulo, 1911 - 1 folh.

Do casamento - Tip. C. Manderbach \& Cia. - São Paulo, 1911 -1 folb.

Defesa crime - E. Graf. Universal - São Paulo, 1912 - 1 folh. Titulos de favor - Siqueira, Nagel \& Cia. - São Paulo, 1913 -1 vol.

A letra de Cambio atual - Siqueira, Nagel \& Cia. - São Paulo, 1913 - 1 vol.

Multiplicaşão da letra de cambio - Siqueira, Nagel \& Cia. São Paulo, 1913, 1 vol. - Tambem publicado In-"Revista da Faculdade de Direito de São Paulo" - vol. 19 - pagg. 111.

Defesa na ação cambial - In- "Revista da Faculdade de Direito de São Paulo" - vol. 19 - pag. 89 e vol. 20 - pag. 9 Tambem publicado por Siqueira, Nagel \& Cia. - São Paulo, 1913 -1 vol.

Defesa na ação cambial - Parte Pratica - Siqueira, Nagel \& Cia. - São Paulo, 1914 - 1 vol. 
Imissão de posse - Agravo - Casa Grafica - São Paulo, 1914 - 1 folh.

Simplificação processual (Tése) - Siqueira, Nagel \& Cia. São Paulo, 1915 - 1 vol. Tambem In-"Revista da Faculdade de Direito de São Paulo" -- vol. 20 - pag. 115.

Filosofia do Direito - Of. do "Estado de São Paulo" - São Paulo, 1915 - 1 vol.

Decreto 2044, anotado - Escolas Profissionais Salesianas São Paulo, 1915 - 2 vols.

Indice das leis mais notaveis do Estado de São Paulo - Siqueira, Nagel \& Cia. - São Paulo, 1916 - 1 vol. - Nova edição em 1920, compreendendo as leis até 1918 - Augusto Siqueira \& Cia. 1 vol. - 3." edição em 1925, comprcendendo as leis até 1924 - Tip. Siqueira - 1 vol. Parte In-"Revista da Faculdade de Direito de São Paulo" - vol. 20 - pag. 203 e vol. 21 -_ pag. 588.

Da administração das Sociedades anonimas - Siqueira, Nagel \& Cia. - São Paulo, 1916 - 1 vol. Tambem In-"Revista da Faculdade de Direito de São Paulo" - vol. 20 — pag. 217.

Da responsabilidade dos administradores das Sociedades anonimas - Siqueira, Nagel \& Cia. - São Paulo, 1917 - 1 vol. Tambem In-"Revista da Faculdade de Direito de São Paulo -. vol. 21 - pag. 11.

Embargos ao recurso extraordinario 1032 - Of. do "Estado de São Paulo" - São Paulo, 1918 - 1 folh.

Ação de enriquecimento - Letra de Cambio - Of. do "Estado de São Paulo" - São Paulo, 1919 - 1 folh. — Tambem In-"Revista da Faculdade de Direito de São Paulo" - vol. 29 - pag. 3.

Embargos 9780, de Rio Preto - Espindola, Siqueira \& Cia. São Paulo, 1920 - 1 folh.

Quarenta anos de vida forense - Liceu do Sagrado Coração de Jesus - São Paulo, 1921 - 1 vol.

Embargos 10.599 -- A desapropriação da São Paulo Northern - sled. Rio de Janeiro, 1921 - 1 vol.

A reforma constitucional - s|ed. - São Paulo, 1923 - 1 folh.

União Sul-Americana - Jacinto Ribeiro dos Santos - Rio, 1924 - 1 vol.

Questöes de dominio - Vicios de escritura - Embargos Of. de Obras do "Estado de SSão Paulo" — São Paulo, 1927 - 1 foll. A pelação 15.350 - Irmãos Ferraz - São Paulo, 1928 - 1 folh. O Moloch Moderno - s/ed. - São Paulo, 1932 - 1 vol. 1 vol.

Do regime democratico - Editora Ltdia. - São Paulo, s/d. pag. 519.

Cuncurso de credores - In-"Revista de Direito" - vol. 16 - 
Executivo hipotecario - In-"Revista dos Tribunais" - vol. 23 - prag. 161.

Usufruto e fideicomisso - In-"Revista dos Tribunais" - vol. 21 - pag. 377 - Tambem In-"Revista Juridica" - vol. 6 - pag. 448.

Dano moral - In-"Revista dos Tribunais" - vol. 3 -- pag. 55 Tambem In-"Revista Juridica" — vol. 7 - pag. 11.

$O$ art. 550 do codigo civil - In-"Revista dos Tribunais" - vol. 89 - pag. 42.

Das colações - In-"Revista dos Tribunais" - vol. $70 \ldots$ pag. 263.

Prova da filiação legitima - In-"Revista dos Tribunais" — vol. 25 - pag. 133.

E' a epilepsia motivo para a nulidade do casamento? - In-"Revista de Direito" - vol. 32 - pag. 47.

Devedores insolvaveis - In-"O Direito" - vol. 78 -- pag. 438.

Patrio poder - In-"Gazeta Juridica" - vol. 58 - pag. 41 Tambem in - "Revista da Faculdade de Direito de São Paulo" vol. 18 - pag. 67.

Aplicação do codigo civil - In-"Revista Juridica". - vol. 4 - pag. 43.

Diferença entre obrigações corretas e simplesmente solidarias -.In-"Revista da Faculdade de Direito de São Paulo" - vol. 14 pag. 7.

A luta contra o delito - In-"Revista da Faculdade de Direito de São Paulo" - vol. 14 - pag. 67.

Historia Externa do Direito Romano - In-"Revista da Faculdade de Direito de São Paulo" - vol. 14 -- pag. 103.

Regime dotal - In-"Revista da Faculdade de Direito de São Paulo" — vol. 16 pag. 49.

A proposiçãa da ação rescisoria do contrato não induz litispendencia para a ação de dez dias proveniente do mesmo contrato. Todavia, havendo já alguma sentença pronunciando a nulidade do: contrato, o autor não poderá levantar a importancia da execução sem prestar fiança - In-"O Direito" - vol. 42 - pag. 5.

Louvação em demarcações e divisões - In-"Revista dos Tribunais" - vol. 38 - Pag. 445.

Juizo arbitral - In-"Pevista dos Tribunais" - vol. 40 pag. 95.

Inquirição e reinquirição de testemunhas - In-"Revista dos Tribunais" - vol. 42 - pag. 283.

Embargos - Oposição pela parte vencida em primeira e segunda instancias - Aplicação do Art. 32 - N. 1 da lei 2722 de 1927 - Açẫo rescisoria - In-"Revista dos Tribunais" - vol. 68 - pag. 3. 
Prova testemunhavel - sem valor - Direito das testemunhas -. In-"Revista dos Tribunais" -. vol. 69 - pag. 231.

Efeitos da apelação - In-"Revista dos Tribunais" - vol. 27 - pas. 11.

A prescrição das acóes "ex-emptoredhibitoria" e "quanti minoris" no Direito patrio - In-"Revista dos Tribunais" — vol. 2 pag. 361 .

Psicologia Judiciaria - In-"Revista da Faculdade de Direito de São Paulo" - vol. 27 - pag. 163.

Voto secreto - In-"Revista dos Tribunais" - vol. 24 - pag. 3.

Estado de Sitio e eleiçôes - In-"Revista da Faculdade de Direito de São Paulo" - vol. 21 - pag. 355.

Profissôes liberais - In-"Revista da Faculdade de Direito de São Paulo" - vol. 25 - pag. 335.

Democracia e liberalismo - In-"Revista da Faculdade de Direito de São Paulo" - - vol. 25 - pag. 353.

Cheque - Incorre em penas de estelionato o individuo que, depois de o emitir, retira das mãos do sacado a provisão de fundos? -In-"Revista da Faculdade de Direito de São Paulo" — vol. 86 pag. 220 .

$O$ art. 206 do nosso codigo comercial - (Idem) - vol. 43 pag. 431.

o Tratado de Direito Comercial do Dr. Carvalho de Mendonça (Idem) - vol. 60 - pag. 3.

Das obrigações em materia comercial - (Idem) - vol. 54 pag. 3 .

A letra de cambio atual -. In-"Revista da Faculdade de Direito de São Paulo" — vol. 19 - pg. 135.

Regulamentação - In-"Revista da Faculdade de Direito de São Paulo - vol. 18 - pag. 157.

Titulo de favor - In-"Revista da Faculdade de Direito de São Paulo" - vol. 19 - pag. 211.

Parecer sôbre o projeto do Dr. Inglez de Souza - In-"Revista da Faculdade de Direito de São Paulo" - vol. 21 - pag. 43.

O Escrivão - In-"Revista dos Tribunais" - vol. 37 - pag. 284.

Segredo profissional - In-"Revista dos Tribunais" — vol. 66 - pag. 3.

Proventos da profissão - In-"Revista dos Tribunais" — vol. 36 - pag. 83.

O Juiz - In-"Revista dos Tribunais" - vol. 36 - pag. 194.

Hipnotismo e responsabilidade - In-"Revista dos Tribunais" - vol. 35 - pag. 177.

Facundação artificial - Germen de cadaver - Paternidade In-"Revista de Direito" - - vol. 48 - pag. 293. 
Fundamento do Direito - Escolas afirmativas - In-"Revista de Direito" - vol. 71 - pag. 430.

O Direito Romano e o seu metodo - In- "Gazeta Juridica" vol. 33 - pag. 3 .

Congresso Medico - In-"Revista Juridica" - vol. 5 - pag. 31.

Jurisconsultos brasileiros - In-"Revista Juridica" — vol. 3 pag. 193.

Apontamento sôbre a Ord. L. 4 T. 47 pr. -- In-"Revista da Faculdade de Direito de São Paulo" - vol. 15 — pag. 83.

Primeira lição sôbre direitos de familia - In-"Revista da Faculdade de Direito de São Paulo" — vol. 15 - pag. 145.

Direito penal - In-"Revista da Faculdade de Direito de São Paulo" - vol. 18 - pag. 9.

Deposito ou consignação - In-"Revista da Faculdade de Direito de "São Paulo" -- vol. 20 - pag. 99.

Das assembléas de acionistas - In-"Revista da Faculdade de Direito de São Paulo" - vol. 20 - pag. 179.

Opulencia e miseria - In-"Revista da Faculdade de Direito de São Paulo" -.. vol. 23 - pag. 247.

Indigencia e socorros - In-"Revista da Faculdade de Direito de São Paulo" - vol. 23 - pag. 253.

Função do processo - In-"Revista da Faculdade de Direito de São Paulo -.. vol. 23 — pag. 305.

O Eclipse do Liberalismo - In-"Revista da Faculdade de Direito de São Paulo" - vol. 23 — pag. 317.

Conservação dos recursos naturais - In-"Revista da Faculdade de Direito de São Paulo" — vol. 22 - pag. 129.

Problemas sociais -.- In-"Revista da Faculdade de Direito de São Paulo" - vol. 22 - pag. 149.

A capital no planalto de Goyaz - In-"Revista da Faculdade de Direito de São Paulo - vol. 22, pag. 205.

A missão dos escóis - In-"Revista da Faculdade de Direito de São Paulo - vol. 26 -. pag. 41.

$O$ dever dos moços - In-"Revista da Faculdade de Direito de São Paulo" - vol. 26 - pag. 155.

Casamentos em consulados - In-"Revista da Faculdade de Direito de S. Paulo" - vol. 30, - pag. 213.

Sucessão de filhos adulterinos - Idem, pag. 281.

$O$ desarmamento e a Paz internacional - In-"Revista da $\mathrm{Fa}$ culdade de Direito de S. Paulo" - - vol. 30 — pag. 439.

Diplomacia universitaria - Academia Argentina no Brasil In-"Revista da Faculdade de Direito de S. Paulo" - vol. 21 -pag. 607 . 
A conselheiro Rui Barbosa - Idem - vol. 22 - pag. 241.

Sepulturas perpetuas - Idem - vol. 23 - pag. 269.

\section{JOÃO PASSOS}

Apelação civel 2285. (Em colaboração com Coutinho de Lima e Gama Cerqueira) - Tip. Pauperio \& Cia. - S. Paulo, 1901 - 1 folh.

Agravo 2839, de Ribeirão Preto - (Em colaboração com Coutinho de Lima e Gama Cerqueira) - Tip. Pauperio \& Cia. - São Paulo, 1901.

Embargos 10.599 - s|ed. - São Paulo, 1901.

Livramento condicional - In-"Revista do Supremo Tribunal" - 1914 - pag. 15.

Campanha de descrédito movida pela Northern Railroad Co. Contra o Estado de São Paulo - Secção de Obras do "Estado de São Paulo" - São Paulo, 1921.

Diogenes de Medeiros - sled. - Rio de Janeiro, 1931.

JOAQUIM DE ALMEIDA LEITE MORAIS JUNIOR

São deficientes as disposições do art. 169 do codigo em relação á repressão do perjurio (Tése) - s/ed. - São Paulo, 1883 - 1 folh.

Qual o melhor dos sistemas penitenciarios conhecidos? - In-"O Direito" - vol. 32 -- pag. 481.

\section{JOSE' PINTO SOUZA DANTAS}

Incompetencia do tutor para autorizar o casamento do pupilo — In-"O Direito" - vol. 97 - pag. 90.

Os padrastos não podem ser tutores de seus enteados - In-"O Direito" - vol. 97 — pag. 91.

\section{LEOPOLDO TEIXEIRA LEITE}

Nulidade de contrato - Ação sumaria - Tip. "Jornal do Comercio" - Rio de Janeiro, 1901 - 1 folh.

Gestão de negocios - Apelação - Tip. do "Jornal do Comercio" - Rio de Janeiro, 1903.

Ação de reivindicação — Tip. "Jornal do Comercio" - Rio de Janeiro, 1905.

Pedido de indenização do sublocatario contra o desapropriante - Ação ordinaria -- Tip. "Jornal do Comercio" - Rio de Janeiro, 1910.

Homologação de sentença estrangeira de habilitação de herdeiros - Apelação - Tip. do "Jornal do Comercio" — Rio de Janeiго, 1911. 
A industria do Sal - Tip. do "Jornal do Comercio" - Rio de Janeiro, 1914.

Pode a cooperativa de crédito estabelecendo armazem geral, emprestar sôbre warrant? - In-"Revista do Direito" - Tomo 74 pag. 303 .

Conhecimento do deposito é titulo habil para constituir penhor? - In-"Revista do Supremo Tribunal - vol. 26 - pag. 281 - Tambem In-"Revista de Direito" - Tomo 58 - pag. 259 e Tomo 66 pag. 42.

Endosso de warrant - In-"Revista do Supremo Tribunal" Vol. 41 - pag. 358 - Tambem In-"Revista de Direito - Tomo 61 -- pag. 32 .

Deposito irregular em armazem geral - In-"Revista dos Tribunais" - vol. 57 - pag. 237 - Tambem 【n-"Revista de Direito" - Tomo 30 - pag. 26.

Circulaşâo irregular de Titulos emitidos por armazem geral In-"Revista dos Tribunais" - vol. 55 pag. 209 - Tambem In-"Revista de Direito" -. Tomo 76 - pag. 206.

$O$ armazem geral $e$ o direito de retenção - In-"Revista dos Tribunais" - vol. 56 - pag. 3. - Tambem In-"Revista de Direito" - Tomo 77 - pag. 402.

Fiscalização de armazem geral - In-"Revista dos Tribunais" — vol. 49 - pag. 8 - Tambem In-"Revista do Direito -. Tomo 71 - pag. 254.

Warrants - E' transferivel o recibo de depósito? - In-"Revisla dos Tribunais" - vol. 47 -.- pag. 258 - Tambem In-"Revista de Direito - Tomo 69 - pag. 407.

Warrant agricola - In-"Revista de Direito" - Tomo 72 e 75 - pags. 317 e 198.

Armazens gerais - In-"Revista de Direito" - Tomo 82 - pags. 291 e 516.

Ação regressiva do portador do warrant - In-"Revisla de Direito" - Tomo 76 - pag. 10.

Exposição justificativa de projeto de lei sôbre armazenagens gerais - In-"Revista de Direito" - Tomo 82 - pag. 31.

Retirada parcial de mercadorias em armazenagens gerais - InRevista de Direito" - Tomo 84 - pag. 407.

Na açấo de desapropriação o mandado de imissão de posse, para produzir os efeitos legais, deve se intimado pessoalmente ao réu? — In-"Revista de Direito" - vol. 11 -. pag. 453 - Tambem In-"Gazeta Juridica" - vol. 51 - pag. 418.

Arrecadação de bens - Herdeiros - Habilitação - In-"Revista de Direito" - Tomo 19 - pag. 51. 
Arbitramento de vinlena - In-"Revista de Direito - Tomo 13 -. pag. 44.

Antes de decretada a separação judicial pode a mulher casada propor ação de alimentos? - In-"O Direito" -_ vol. 106 - pag. 184.

Seguro de mercadorias em armazenagens gerais - In-"Revista de Direito" - Tomo 57 - pag. 248.

\section{LUIZ B. MARQUES PITALUGA}

E' o promotor publico, como recorrido, obrigado a arrazoar os recursos de pronúncia, sem ter pedido vista, para isso, na fórma do art. 73 da lei de 31 de Dezembro de 1841 - In-"O Direito" - vol. 48 - pag. 20.

Caso de un inquerito policial, remetido á autoridade judiciaria não resulte indicio veemente de culpa contra alguem, por crime inafiancavel, é a dita antoridade obrigada a remetê-lo ao promotor prublico da comarca, ou pode, independente da audiencia dêsse funcionario, fazê-lo arquivar? - In-"O Direito" - vol. 51 - pag. 489.

Custas em habeas corpus -.. In-"O Direito" — vol. 56 - pag. 568.

A sentença de pronúncia é impedimento para a concessão de uma ordem de habeas corpus? - In-“O Direito" - vol. 57 pag. 11.

A mãe, no regime atual, tem direito de repetir as despesas feitas com seus filhos - In-"O Direito" - vol. 59 - pag. 585.

$O$ juiz dos casamentos pode deixar de realizar o solicitado pelo ofensor de uma menor toda vez que, por qualquer causa, ela não possa dar livremente o seu consentimento? - In-"O Direito" vol. 59 - pag. 42.

Qual o recurso que tem o réu definitivamente condenado quando o seu processo é evidentemente nulo? - In-"O Direito" - vol. 69 - pag. 5.

Têm as mães o direito de fazer substituição pupilar? - In-"O Direito" - vol. 69 - pag. 6.

\section{MANOEL IGNACIO CARVALHO DE MENDONÇA}

A intervenção e a doutrina de Monroe - Tip. Modelo - Curitiba, 1896 - 1 vol.

o poder judiciario no Brasil - Adolfo Guimarães - Curitiba, 1899 - 1 vol.

Doutrina e prática das obrigações ou tratado geral dos direitos de credito - Tip. Lit. Paranaense - Curitiba, $1908-1$ vol. Rios e aguas correntes em suas relações juridicas - Anibal Rocha \& Cia. - Curitiba, 1909 - 1 vol.

Contratos no Direito civil brasileiro ... Francisco Alves \& Cia. - Rio de Janeiro, 1911 - 2 vols. 
A vontade unilateral nos direitos de credito - Francisco Alves \& Cia. - Rio de Janeiro, 1916 - 1 vol.

Da ação rescisoria das sentenças e julgados - Francisco Alves \& Cia. - Rio de Janeiro, 1916 - 1 vol.

Do usufruto e da habitação no codigo civil brasileiro - Candido de Oliveira - Rio de Janeiro, 1922 - 1 vol.

Considerações sóbre a inviolabilidade da palavra no Congresso - In-"O Direito" — vol. 86 - pag. 449.

$O$ irmão bilateral reconhecido com sua irmã em testamento do pai comum concorre à herança desta com o conjuge sobrevivente, excluidos os irmãos simplesmente consayuineos embora reconhecidos no mesmo testarrento - In-"O Direito" - vol. 43 - pag. 161.

Dos contratos - "In-"O Direito" -- vol. 101 - pag. 82.

Evolução das municipalidades modernas - In-"O Direito" vol. 102 - pag. 201.

A liberdade profissional - In-"O Direito" - vol. 99 - pag. 321.

O crime de conspiracãa contra o govêrno dos Estados é da competencia da magistratura federal ... In-"O Direito" - vol. 61 pag. 5 .

Do conceito juridico dos direitos reais - In-"Revista de Direito" - Tomo 37 - pag. 213.

$O$ anweisung $e$ os contratos consigo mesmo - In-"Revista de Direito" - Tomo 12 - pag. 29.

O Homestead - In-"Revista de Direito" - Tomo 36 - pag. 213.

Das concessões administrativas e da natureza juridica da garantia de juros - In-"Revista do Supremo Tribunal" - 1914 - pag. 215.

Concordata preventiva de menos de $20 \%$ - In-"Revista Juridica" - vol. 1 - pag. 250.

Da instituição do Tribunal do juri - In-"Revista Juridica" vol. 1 - pag. 44.

Contratos celebrados por comerciantes em concordatas preventivas - In-"Revista Juridica" - vol. 1 - pag. 251.

Inteligencia do art. 7. do Decreto 181 de 24 de Janeiro de 1890 -- In-"Revista Juridica" - vol. 3 - pag. 208.

Direito de acrescer nas heranças e legados - In-"Revista Juridica" - vol. 3 - pag. 44.

\section{MANOEL ALGUSTO DE ALVARENGA}

Consolidaçâo das leis hipolecarias - Tip. Andrade, Mello \& Cia. - Sáo Paulo, 1899 - 1 vol.

Precedencia do ato civil ao ato religioso do casamento - In-"Gazeta Juridica" - vol. 2 -- pag. 23. 
RAFAEL CORREA DA SILVA SOBRINHO

Emprestimo ao cofre de órfãos - Bens de defuntos $e$ ausentes - Feição destas instituições - (Tése) - Cia. Predial-São Paulo, 1893 - 1 folh.

Discursos - Tip. do "Diario da Manhã" - São Paulo, s/d.

Conferencia sobre o juri - In-"Revista da Faculdade de Direito de S. Paulo" - v. 18 - pag. 7.

Da menagem e da lésa — magestade - Idem - v. 10 - pag. 13.

Elogio historico do Dezembargador Aureliano Coutinho - Idem, v. 5 - pag. 323 .

Materia de desapropriação - Idem - v. 18 - pag. 27.

$O$ artigo IV da lei hipolecaria - Idem - v. 6 - pag. 169.

Reunir e remitir e seus propinquos - Idem - v. 4 - pag. 71.

TEOFILO DIAS DE MESQUITA

Quem é o proprietario dos bens da igreja? - (Tése) - Tip. do Comercio -- São Paulo, 1883 - 1 folb. — Tambem In-"O Direito" - vol. 33 - pag. 321 .

\section{2}

\section{ALCEBIADES UCHOA}

Ação ordinaria de petição de herança - Tip. da Casa Marinoni - Franca, 1903 - 1 vol.

\section{ALFREDO BERNARDES DA SILVA}

Pacto comissório — In-"Revista de Direito" - vol. 107 pag. 43.

Interpretação e aplicação do preceito do art. 1080 do Codigo Civil - Estudos juridicos e sociais - vol. 1 - pag. 145.

Usufruto e fideicomisso - In-"O Direito" - vol. 94 - pag. 333.

Das obrigações em geral -- In-"Revista de Direito" - Tomo 1 - pag. 287.

Bens inalienaveis e impenhoraveis não respondem, nem mesmo após a morte do legitimario, pelas dividas que êste contraiu nas vigencias das clausulas - In-"O Direito" — vol. 109 - pag. 88.

Filho adulterino - Adoção - consequencias - In-"O Direito" - vol. 55 - pag. 286.

Predios urbanos - arrendamento - Recondução tácita - Inadmissibilidade -- In-"O Direito" - vol. 29, pag. 61. 
Bens herdados de filhos do segundo leito - Falecimento do binubo - Para quem passam tais bens - Direito adquirido etc. - In-"O Direito" - vol. 51 - pag. 469.

Revisâo de contrato de locação de predio urbano por impossibilidade juridica de sua execução - In-"O Direito" — vol. 77 ... pag. 212.

Nulidade de casamento - Erro essencial sôbre a pessoa do outro cônjuge - Ação - Prescrição - In-"O Direito" — vol. 82 -- pag. 536.

Filhos ilegitimos reconhecidos por ambos os progenitores - $\mathrm{Pa}$ trio poder -- In-"O Direito" — vol. 72 - pag. 296.

o padrasto pode ser tutor — In-"O Direito" - vol. 72 pag. 301.

Venda de bens de menores sob patrio poder - In-"O Direito" - vol. 63 - pag. 53.

Servidões - Como se constituem - In-"O Direito" - vol. 74 - pag. 32 .

Eleitos da confusão nas relações juridicas de contratos de locaçâo cum sublocações - In-"O Direito" - vol. 79 - pag. 77.

Incêndio parcial do prédio locado - Como deve ser empregalla a indenização quando o seguro esta a cargo do locatario - In-"O Direito" - vol. 30 - pag. 64.

Constituição do dote pelo nubente-marido á futura esposa In-"Revista de Direito" - vol. 80 - pag. 50 - Tambem In-"Pandectas Brasileiras" - vol. 1 - 1." Parte - pag. 211.

Ação rescisoria de anulação de casamento - Partilha de bens do extinto casal - "In-Revista de Direito" - vol. 80 - pag. 488.

Fixação de aluguel com carater penal - In-"Revista de Direito" - vol. 74 - pag. 451.

Adquirente de predio - Quando sómente é obrigado a respeitar a locação - Realisação arbitraria do contrato de locação In-"O Direito" - vol. 74 - pag. 464

Repetição do pagamento indébito - Inteligencia do art. 969 do. codigo civil - Execução de sentença - Embargos de nulidade Admissibilidade em face do art. 353 ns. 3 e 5 do Codigo do processo civil e comercial do Distrito Federal - In-"Revista de Direito" - vol. 91 - pag. 489.

Mandato - Procuração - Clausula "fazer o que for necessario" - o que compreende -- Hipoteca - Impotualidade da prestação de juros - Vencimento da divida - Aplicação do art. 762 do Codigo Civil - In-"Revista Juridica" - vol. 90 - pag. 45.

Os filhos adotivos e a herança do pai adutante - In-"Revista do Supremo Tribunal" - vol. 23 - pag. 289. 
Zonas fiscais - In-"Revista do Supremo Tribunal" - vol. 8 - pag. 87.

Servidões por destinação do proprietario - In-"Revista do Supremo Tribunal" — vol. 8 - pag. 285.

o Codigo Civil -. Discurso - In-"Revista do Supremo Tribunal - vol. 10 -. pag. 91 .

Inalienabilidade imposta pelo testador - In-"Revista do Supremo Tribunal" -.. vol. 10 — pag. 339.

O regime da comunhão de bens e seus efeitos na falencia "In-"Revista do Supremo Tribunal - vol. 11 - pag. 485.

Alienação de bens de raiz pelo marido - In-"Revista do Supremo Tribunal" - vol. 12 - pag. 87.

O usufruto sôbre apolices da divida pública - In- "Revista do Supremo 'Tribunal" - vol. 12 -... pag. 247.

Fideicomisso - Sentença nula - In-"Revista do Supremo Tribunal" - vol. 15 - pag. 585.

Nulidade de testam?nto cerrado - In-"Revista de Jurisprudencia Brasileira” - vol. 2 - pags. 161 e 181.

Do condominio entre cônjuges casados no regime de absuluta separação de bens — In-"Revista de Jurisprudencia Brasileira" vol. 5 - Fas. 13.

Do direito e preferencia entre condominios - In-"Revista Judiciaria Brasilcira" - vol. 1 ... Fas. 3.

Conceito moderno da obrigação e do valor" economico - In-"Revista Forense" - vol. 42 - pag. 239.

Do privilegio do empreiteiro - In-"Revista Juridica" - rol. 2 - pas. 395.

A venda de bens imoveis de órfãos sob o patrio poder sem hasta publica - In-"Revista Juridica" - vol 25 - pag. 5.

Pessoas nalurais e pessoaes juridicas - In-"Revista Juridica" vol. 3 - pag. 200.

Substituiçẫo fideicomissaria - In-"Revista Juridica" - vol. 1 - pag. 20.

A homologacão judicial do acôrdo entre os portadores de debentures de Sociedades anonimas e estas sociedades é apenas uma formalidade complementar do contrato constante daquele acôrdo. Da sentença homologatoria não cabe recurso algum nos proprios autos do acôrdo — In-"O Direito" - vol. 113 - pag. 608.

Socicdades anonimas - In-"Revista dos Tribunais" - vol. 6 - pags. 258 e 336.

Uutorga uxoria - In-"Revisla dos Tribunais" - vol. 87 pag. 494. 
Falencia - Ação revocaloria - Prescrição - Inteligencia do art. $60 \leqslant 4 .^{\circ}$ da atual lei das falencias - - In-"Revista dos Tribunais" vol. 87 - pag. 12 .

Sociedade comercial por tempo indeterminado - Decretação de sua dissolução e liquidação no decurso do cumprimento de concordata preventiva — Admissibilidade - In-"Revista de Direito" vol. 90 -- pag. 235 .

Patentes de invenção - Contrato de cessão mediante partilha de lucros - Rescisão - Perdas e danos - In-"Revista de Direito" — vol. 92 - pag. 32 .

Letra de cambio - Protesto em dia feriado - In-"Revista de Direito" — vol. 41 - pag. 41.

Menor comerciante -- Alienação de bens de raiz - Apolices da divida publica -- In-"O Direito" -.. vol. 59 -... pag. 40 - Tambem In-"Revista do Supremo Tribunal" - vol. 18 - pag. 377.

Falencia do executado comerciante - In-"O Dircito" - vol. 78 pag. 256.

Impostos sôbre lucros comerciais - In-"O Direito - vol. 60 - pag. 250.

Protesto de letra de cambio em dia feriado - "In-Revista do Supremo Tribunal" - vol. 7 - pag. 241 - Tambem In-"Revista Juridica" - vol. 1 - pag. 207.

O contrato de penhor em face da lei de falencias - In-"Revista do Supremo Tribunal" — vol. 29 -.. pag. 381.

Contas assinadas com clausula á ordem - "In-Gazeta Juridica" vol. 49 - pag. 11.

Sociedades anonimas - Conversão de ações ao portador - Direito de voto - In-"Pandectas Brasileiras" - vol. 4 - 1." Parte - pag. 70 .

Contas assinadas - Efeitos juridicos resultantes da circulação mediante desconto por endosso - In-"Pandectas Brasileiras" — vol. 4 - 1." Parte - pag. 108.

Dos efeitos da guerra nas relações cambiais - In-"Revista Juridica" — vol. 2 - pag. 205.

Testamento arguido de falso - In-"O Direito" - vol. 83 pag. 5 .

I'ma questâo de imposto estadual sòbre capital de uma empresa estrangeira de melhoramentos publicos, realizado e existente no estrangeiro - Emp. Grafica "Revista dos Tribunais" — Sāo Pau!o. 1931 -1 folb.

Embargos de terceiro senhor e possuidor (em colaboracão com Souza Ribeiro, Lafayette Rodrigues Pereira e Silva Cosla) - Tip. Salesiana - São Paulo, 1901 - 1 folh. 
Apelação civel 3744, do Distrito Federal - Tip. do "Jornal do Comercio" - Rio de Janeiro. 1922 - 1 folh.

$O$ valor probante dos traslados e certidóes de notas publicas In-"Revista dos Tribunais" - vol. 67 - pag. 405 - Tambem In-"Revista de Direito" - vol. 93 - pag. 458.

Juizo Arbitral - Exclusão dos juros da móra -.. Embargos de declaração - "Diario do Fôro" - vol. 2 - pag. 223.

Ação de investigaçãa de paternidade intentada por filho natural contra os herdeirus dos herdeiros do suposto pai - In-"Revista de Direito" - vol. 88 - pag. 492.

A avocação dos autos de deposito e apensação aos de despejo In-"Revistla de Direito" - vol. 79 - pag. 314.

Cabe ação rescisoria da sentença que julga boa a penhora em executivo nulo por ilegitimidade de partes e impropriedade de ação - Carencia de ação - Penhora de bens "pro-indiviso" - E' permitida a oposição nas ações rescisurias - In-"Revista de Direito" - vol. 54 - pag. 287.

Banimento da familia imperial - In-"Revista de Direito" vol. 55 - pag. 467.

Acção de nulidade de casamento - Sentença que a decretou soberanamente passada em julgado - Efeitos - In-"Revista de Direito" - - vol. 108 - pag. 545.

Caução de opere demoliendo - Perdas e danos - In-"Revista Juridica" - vol. 6 - pag. 484.

Do imposto do selo nas herançus e legados - In-"Revista Juridica" - vol. 6 - pag. 248.

Do aresto ou embargo - In-"Revista Juridica" -- vol. 3 pag. 426.

$O$ poder de policia do Estado e o respeito ás sentenças judiciais - In-"Pandectas Brasileiras" - vol. 1 - 1." Parte - pag. 216.

BERNARDINO DE LIMA

Apontamentos de Díreito e Economia Politica - Leroy King \& Cia. - São Paulo - $1882 \ldots 1$ vol. 1 vol.

Economia rural - Tip. de Forum - Ouro Preto - 1896 -

O contencioso administrativo na Republica - In-"Revista da Faculdade Livre de Minas Gerais" -- vol. 1906 - pag. 17.

Legislậão de Minas - In-"Revista da Faculdade Livre de Minas Gerais - vol. 1894 - pag. 51.

DARIO ACGUSTO FERREIRA DA SILUA

Completa privação de sentidos e de inteligencia - In-"Revista do Forum" - vol. 5 - pag. 574. 
A Inconstitucionalidade da lei e o Poder Judiciario - In-"Revista do Forum" - vol. 6 -- pag. 1.

\section{JOSE' MARCONDES DE ANDRADE FIGLEIRA}

Pretendida falsidade da firma do emitente de uma promissoria de 60:000\$v00 - Ação executiva - Alegações finais do réu - Augusto Siqueira \& Cia. - São Paulo - 1917 - 1 folb.

\section{LLIZ PORTO MURETZSON DE CASTHO}

Reivindicação de posse -..- Sentença de $10^{\circ}$ instancia - Santos Tip. "A Cidade de Santos" - 1903 - 1 folh.

JOSE' ROBERTO LEITE PENTEADO

Cessão de bens - Agravo de instrumento - Edelbrock \& Moreira - São Paulo - 1893 - 1 folh.

\section{PELINO JOAQUIM DA COSTA GUEDES}

Oração funebre recitada na sessão comemorativa do falecimento do academico Antonio do Nascimento Camargo - Tip. Comercial - São Paulo - 1880 - 1 folb.

Discurso proferido por ocasião da manifestação academica ao Conselheiro Ducete de Azevedo - Tip. Popular - Sāo Paulo 1881 - 1 folh.

Biografia de Amaro Cavalcanti - Tip, Leuzinger - Rio de Janeiro, $1897-1$ vol.

Tratado de Extradição entre o Brasil e o Perú - In-"Revista do Supremo Tribunal" - - vol. 19 - pag. 175.

o juiz de Direito em disponibilidade não pode ser considerado magistrado para os efeitos de ser tido como incompativel a exercer cargos na policia do Distrito Federal - In-"O Direito" - vol. 113 - pag. 613.

\section{3}

\section{ALONSO GUAYANAZ DA FONSECA}

Posse de vereadores - Ribeirão Preto - Vanord \& Cia. - São Paulo, 1896 - 1 folh.

Penhora - Apelação civel 1610 - Tip. Industrial São Paulo, 1898 - 1 folh.

Ação de nulidade e escritura - Apelação civel - Tip. Industrial - São Paulo, 1898.

Ação recisoria e de indenização - Espindola \& C. - São Paulo, 1908 - folh. 


\section{ANTONiO ALVES DA COSTA CARVALHO}

Ação ordinaria -- Razões do réo - (Em colaboração com Jayme de Moraes Salles) - J. Ladeira - Campinas, 1906 - 1 folh.

Lesão enormissima - . Razões finais do réo - (Em colaboração com José Manoel Lobo, Paulo Lobo e Octavio da Costa Carvalho) - J. Ladeira - Campinas, 1908 - 1 folh.

\section{ANTONIO JOSE CAPOTE VALENTE}

Monopolio de serviço funerario - Ação ordinaria - Tip. da Cia. Industrial de São Paulo — São Paulo, 1892 - 1 folh.

Credor hipotecario - Apelação civel 630 . Magalhães \& Gerlach - São Paulo, 1896 - 1 folh.

Cobrança de multa por arrependimento - Apelação civil 1329, da Capital - Espindola Siqueira \& C. - São Paulo, 1897 - 1 folb.

A questão do cemiterio do Saboó - Espindola, Siqueira \& Cia. - São Paulo, 1897 - 1 folh.

Apelação civel 6427, da Capital - Tip. Ideal - São Paulo, 1907 - 1 folb.

\section{ALVARO JOSÉ GONÇALVES CHAVES}

Discurso em honra de Garibaldi - Tip. Leuzinger \& Filbos Rio de Janeiro, 1883 - 1 folh.

Discurso pronunciado na sessão magna de 20 de Setembro de 1885 do Clube Republicano Rio Grandense, no Theatro "Lucinda" do Rio de Janeiro - Tip. Leuzinger \& Filhos - Rio de Janeiro, 1885 - 1 folh.

\section{ESTEVAM AUGUSTO DE OLIVEIRA}

Agravo 2820, de Santos - Tip. Industrial - São Paulo, 1901 -1 folh.

Agravo 3051 -... Duprat \& Cia. - São Paulo, 1902 - 1 folh.

Tutela - Póde exercê-la a binuba sobre os filhos do leito anterior. uma vez autorizada pelo marido. - (Em colaboração com Teodomiro Dias) — S/Ed. - São Paulo, 1933 - 1 folh.

E' licito á viuva, perante o direito pátrio, renunciar a sua meação para exonerar das obrigaçôes do seu casal? - In Revista de Direito - Vol. 7 - pag. 450.

\section{FRANCISCO EUGENIO DE TOLEDO}

Leis e formulas processuais - Casa editora Mofreita - Sāo Paulo, $1904-1$ vol. 
Contratos e obrigações mercantis -- Casa editora Mofreita São Paulo, 1905 - 1 vol.

Nulidade do processo civil e comercial - Tip. J. P. Cardozo São Paulo, 1906 - 1 rol.

Confissão judiciaria - Augusto Siqueira \& Cia. - São Paulo, 1917 - 1 vol.

Manual de Direito civil das pessoas - Empresa Editora Brasileira - São Paulo, 1920 - 1 vol.

Atentado ao pudor - Empresa Editora Brasileira - Sāo Paulo, 1921 -. 1 vol.

Análise da Constituição Federal - Emp. Ed. Bras. - São Paulo, 1922 - 1 vol.

Historia da Independencia do Brasil - In-"Rev. do Instituto Historico e Geografico Brasileiro" - Tomo 107 - vol. 161 - pag. 105.

O apopletico pode lestar? - In-"Gazeta Juridica" - vol. 45, pag. 124.

Vendas ad corpus e ad mensuram - In-"O Direito" vol. 104 pag. 329.

Recurso extraordinario - In-"O Direito" -... vol. 104 - pag. 5. Hipoteca feita por quem é casado com mulher de 21 anos - In"Oi Direito" vol. 104 - pag. 489.

\section{JULIO CESAR FERREIRA DE MESQUITA}

Carta testemunhavel do juizo seccional de São Paulo - (Em colaboração com Eugenio Egas e Alfredo Pujol) - Tip. Carlos Gerke \& Cia. - São Paulo, 1896 - 1 folb.

O coronel Joaquim Quirino dos Santos - In-"Revista do Instituto Historico e Geografico de São Paulo" - vol. 8 - pag. 170.

\section{LEÃO LUIZ RJBEIRO}

Ação ordinaria - Foro comercial de Santos - Tip. União Tipografica - Santos, 1887 - 1 folh.

Acão Ordinaria comercial - Tip. do "Diario de Santos" - Santos, $1887-1$ folh.

A pelação comercial 1569, de Santos - Tip. Jorge Seckler \& Cia. - São Paulo, 1888 - 1 folh.

Apelaçâo comercial 1551, de Santos - Tip. da União Tipugrafica - Santos, 1888 - 1 folh.

Apelação civel 1540, de Sanlos - Tip. da Uniāo Tipografica Santos, 1888 -_ 1 folh.

\section{LUIZ DE TOLEDO PIZA E ALMEIDA}

Apelação civel 1376, da Capital - Maciel \& Filhos - São Paulo, $1898-1$ folh. 
Situação da vila de Piratininga - In-"Revista do Instituto Historico e Geografico de São Paulo” -. vol. 23 - pag. 209.

\section{LUIZ CHRISTIANO DE CASTRO}

Inteligencia dos artigos 15,19 e 4. ${ }^{\circ} \& 6 .^{\circ}$ da lei 169 A. de Janeiro de 1890 - In-"O Direito" - vol. 89 - pag. 50.

\section{MANOEL ALVARO DE SOUZA SA' VIANNA}

Esboços criticos da Faculdade de Direito de São Paulo em 1879 - Tip. do Brasil - Rio de Janeiro, 1880 - 1 vol.

Cincoenta anos de existencia - Instituto da Ordem dos Advogados Brasileiros - Imprensa Nacional - Rio de Janeiro, 1894 - 1 vol.

Congresso Juridico Americano - Imprensa Nacional - Rio de Janeiro, $1902-2$ vols.

Traços biograficos de Teixeira de Freitas - Tip. Hildbrand Rio de Janeiro, $1905-1$ vol. 1 vol.

Das falencias - Tip. Hildebrand - Rio de Janeiro, 1907 -

Elementos de Direito Internacional - Tip. do "Jornal do Comercio" - Rio de Janeiro, $1908 \ldots 1$ vol.

L'arbitrage au Brésil - Imprensa Nacional - Rio de Janeiro, 1917 - 1 vol.

Fuertes y débiles - Imprenta Gotelli \& Cia. - Buenos Aires, 1917 - 1 vol.

Pareceres do consultor geral da Republica - Imprensa Nacional - s/d. - Rio de Janeiro, 2 vols.

O Brasil e a Arbitragem Internacional - "Anais da Biblioteca Nacional do Rio de Janeiro" - vol. 9 - pag. 115.

El Papa como persona enternacional - In-"Revista Mexicana de Derecho internacional" - N.* 2 - Junho de 1921.

Organização judiciaria do Distrito Federal — In-"O Direito" vol. 60 - pag. 161 .

Devem as Nações Sul Americanas celebrar tratados permanentes de arbitragem? Qual a extensão que devem ter esses tratados? - In "O Direito" - vol. 85 - pag. 44.

O trafico e a diplomacia brasileira - In-"Revista do Instituto Historico e Geografico Brasileiro" - Congresso de Historia Nacional - vol. 5 - pag. 537.

\section{MARTIM FRANCISCO RIBEIRO DE ANDRADE SOBRINHO}

Apelação 1614, da Capital - Andrade, Mello \& Cia. - São Paulo - $1898-1$ folh. 


\section{PEDRO AUGUSTO CARNEIRO LESSA}

Os proibidos de comerciar podem autorizar suas mulheres no exercicio do comercio? (Tése) - Tip. da Provincia de São Paulo - São Paulo, 1884 - 1 folb. — Tambem in-"O Direito" vol. 45 pag. 161.

Passa ao comprador da herança o direito de acrescer? - (Tése) -- Tip. do "Diario Popular" - Sāo Paulo, 1888 - 1 folh.

Memoria historico-academica do ano de 1888 - Leroy King São Paulo, $1889-1$ folh.

Sucessão - Apelação civel - Embargos - Espindola Siqueira \& Cìa. - São Paulo, 1895 - 1 folh.

Uniformidade do Direito Brasileiro - Interpretação dos arts. 34 n. $.^{\circ} 23,63$ e 65 n. 2 da Constituição Federal - Siqueira \& Cia. São Paulo, 1899 - 1 vol.

Discurso proferido na Faculdade de Direito de São Paulo por ocasiâa da colação de gráu dos bacharelandos de 1896 - Espindola \& Siqueira — São Paulo, 1896 - 1 folh.

Questão de responsabilidade civil - Apelação 2622 - Tip. Industrial - São Paulo, 1900 - 1 folh.

Agravo 2887, de Campinas - Tip. Industrial -.. São Paulo, 1901

1 folh.

Apelaçâao civel 3117, de Ribeirão Preto - Tip. Industrial São Paulo, 1901.

Resumo completo das preleções de Direito Romano - 2." ed. -s/ed. - São Paulo, 1901 - 1 vol.

Nulidade de testamento - Ação ordinaria - Alegações finais da ré - Duprat \& Cia. - São Paulo, 1903 - 1 folh.

Agravo 3865, de Campinas -- Duprat \& Cia. - São Paulo, 1904 -1 folb.

Executivo hipotecario - Apelação civel 3977, de Campinas Duprat \& Cia. - São Paulo, 1904 -- 1 folb.

Nulidade de testamento - Embargos 3996, de Campinas - Duprat \& Cia. - São Paulo, 1904 - 1 folh.

Restituição de menores - Embargos 388\%, de Limeira - Andrade \& Mello - São Paulo, 1905 - 1 folb.

Contrato de abertura de credito - Apelação civel 4742, da Capital - Duprat \& Cia. - São Paulo, 1906 - 1 folh.

Pontos de filosofia - Espindola \& Cia. - São Paulo, 1907 1 vol.

Dissertações c polemicas - Tip. do "Jornal do Comercio" Rio de Janeiro, 1909 - 1 vol.

Estudos de filosofia do Direito - Tip. do "Jornal do Comercio"

- Rio de Janeiro, 1912 - (2." edição - Livraria Francisco Alves

- Rio de Janeiro, 1916 - 1 vol.). 
Do poder judiciario - Francisco Alves \& Cia. - Rio de Janeiro, $1915-1$ vol.

Discursos e conferencias - Tip. Rodrigues \& Cia. - Rio de Janeiro, 1916 - 1 vol.

Acumulações remuneradas - s/ed. - Rio de Janeiro, 1920 1 vol.

Da naturalização e seus efeitos na orbita do Direito Civil - Iu "O Direito" - vol. 93, pag. 165 - (Tambem In-"Revista de Direito" - vol. 4 -. pag. 271 - (Tambem in-"Revista da Faculdade de Direito de São Paulo" - vol. 11 - pag. 215).

Credor por benfeitorias - In-"Revista de Direito" - vol. 1 pag. 57.

Prelação das hipotecas anteriores ás dividas fiscais - In "O Direito" - vol. 30 - pag. 23 - Tambem In-"Revista da Faculdade de Direito de São Paulo" - vol. 13 - pag. 37.

Da isenção do imposto de transmissão de propriedade nas tornas ou reposições - In-"Revista de Direito" vol. 11 - pag. 443 Tambem In-"Revista da Faculdade de Direito de São Paulo" — vol. 12 - pag. 117.

Responsabilidade dos empresarios de transportes - In-"Revitsa de Direito" - vol. 10 - pag. 235.

$E$ ' transferivel causa-mortis a "spes debitum iri" do fideicommissarios nas substituições condicionais? - In-"Revista de Direito vol. 8 - pag. 393. Tambem In-"Revista da Faculdade de Direito de São Paulo" - vol. 4 - pag. 313.

Póde-se revogar um testamento por uma escritura publica? In-"Revista de Direito" - vol. 6 - pag. 498 - Tambem In-"Revista da Faculdade de Direito de São Paulo" - vol. 5 - pag. 297.

$E^{\prime}$ necessaria a hasta publica para venda de imoveis pertencentes a menores sob o patrio poder? - In-"Revista de Direito" vol. 6 - pag. 19 - Tambem In-"Revista da Faculdade de Direito de Sāo Paulı" - vol. 12 - pag. 97.

Naturalização de subditos estrangeiros, investigação de paternidade - In-"Revista do Supremo Tribunal" — vol. 17 - pag. 237.

A idéia de justiça - In-"Revista do Supremo Tribunal" - vol. 13 - pag. 95.

A simplificação do processo diante dos principios filosoficos do Direito - Trab. e conferencias do Instituto da Ordem dos Advogados Brasileiros, ano 1910 - pag. 91 - Em brochura - Rodrigues \& Cia. - Rio de Janeiro, 1912.

O imposto de industria e profissão - In-"Revista Juridica" vol. 20 - pag. 197.

Casamento de brasileira divorciada de estrangeiro - In-"Revista Juridica" - vol. 7 - pag. 201. 
Do arbitramento dos honorarios de advogados - In-"Gazeta Juridica" - vol. 24 - pag. 81 e 49 - pag. 19.

Da compra e venda de cousas e imoveis "ad corpus" e "ad minsuram" - In-"Gazeta Juridica" — vol. 19 - pag. 81 e vol. 17 pag. 1 e 16 - pag. 5 .

Os socios ou condominos de uma maquina de beneficiar café, ou de uma serraria não poderâa usar de ação communi dividundo, devido $\dot{a}$ indivisibilidade do objeto - In-"Gazeta Juridica" - vol. 41 - pag. 134.

Da complexidade do Direito - Distinção entre moral e direito - Relaçôes do Direito com a sociologia, com a antropologia; a ciencia economia e a politica - In-"Revista da Faculdade de Direito de São Paulo" - vol. 7 - pag. 303.

A teoria de Ihering - In-"Revista da Faculdade de Direito de São Paulo" - vol. 9 - pag. 102.

A arte, a ciência e a filosofia do Direito - In-"Revista da Faculdade de Direito de São Paulo" - vol. 14 - pag. 32.

Ha um direito natural? - In-"Revista da Faculdade de Direito de São Paulo" - vol. 2 - pag. 119.

Que é socialismo? - In-"Revista da Faculdade de Direito de. São Paulo" - vol. 3 - pag. 45.

A escola historica - In-"Revista da Faculdade de Direito de São Paulo" - vol. 11 - pag. 359.

$O$ direito no seculo XIX - In-"Revista da Faculdade de Direito de São Paulo" - vol. 8 - pag. 161. Tambem In-"Revista do Instituto Historico e Geografico Brasileiro" - vol. 68 - 2." parte pag. 507.

O idealismo transcendental ou criticismo de Kant - In-"Revista da Faculdade de Direito de São Paulo" - vol. 10 - pag. 217.

Metodologia juridica - In-"Revista da Faculdade de Direito de São Paulo" - vol. 4 - pag. 5 .

A ideia de justiça - In-"Revista Juridica" - vol. 8 - pag. 193.

Da competencia do Estado para legislar sôbre o processo das justiça locais - In "O Direito" - vol. 107 - pag. 24 e 65 - Tambem In-"Revista da Faculdade de Direito de São Paulo" — vol. 7 pag. 127 e 185 .

Autonomia Municipal - In-"Revista do Supremo Tribunal" 1915 - pag. 565 - Tambem In-"Revista Juridica" - vol. 1 - pag. 5.

Competencia originaria do Supremo Tribunal Federal para conhecer de pedidos de "habeas-corpus" - In-"Revista do Supremo Tribunal" - vol. 14 - pag. 109. Tambem In-"Revista Juridica" vol: 9 - pag. 215.

Intervençâo do Estado em materia de higiene publica - In-"Revista de Direito" - vol. 14 - pag. - 11. 
Caso de dupla nacionalidade - Filhos de italiano nascidos no Brasil - In-"Revista Forense" — vol. 24 - - pag. 9.

Questões de limites entre Estados - In- "Revista Juridica" vol. 20 - pag. 387.

Vencimentos de Empregados Publicos -.. In "Gazeta Juridica" — vol. 47 - pag. 84 .

Sociedade regular e suciedade de fato - In-"Revista de Direito" — vol. 8 - pag. 16 - Tambem In-"Revista da Faculdade de Direito de São Paulo" vol. 10 - pag. 137.

Do processo executivo para a cobrança de honorarios medicos —In-"O Direito" - vol. 70 — pag. 161.

A ação rescisoria - In "Revista de Direito" — vol. 9 pag. 423.

Perpetuação de ação em face do nosso direito - In "Revista Juridica" - vol. 19 - pag. 385.

Prescrição de ação contra a Fazenda Nacional - Citação Seus efeitos -- Contestação da lide - Seus efeitos - In "Gazeta Juridica" - vol. 51 - - pag. 15.

A competencia por situação de causa é especial para as ações contra quem possue a consa dentro de ano e dia - In-"Gazeta Juridica" - vol. 55 - pag. 251.

Congresso juridico brasileiro - In "O Direito" — vol. 107 pag. 349.

Entrada em casa alheia - Repulsa -- Quando é legitima - In "Revista de Direito" - vol. 9 - pag. 225.

João Francisco Lisboa - In "Revista do Instituto Historico e Geografico Brasileiro" - vol. 76 - 1." parte - pag. 65 - Tambem In-"Revista da Academia Brasileira" - Outubro de 1912.

Delito continuado - In "Revista dos Tribunais" - vol. 22 pag. 311.

O preconceito das reformas constitucionais - In "Revista do Brasil" - vol. 1 - pag. 6 e vol. 4 - pag. 351 .

$O$ direito segundo a filosofia teologica - In "Revista da Facu!lade de Direito de São Paulo" - vol. 13 - pag. 155.

Passa ao comprador da herança o direito de acrescer? - In "Revista da Faculdade de Direito de São Paulo" - vol. 11 - pag. 241.

Barão do Rio Branco - In "Revista da Faculdade de Direito de São Paulo" - vol. 16 - pag. 9.

Tribunais para crianças - In "Gazcta Juridica" — vol. 55 pag. 245.

A questão do Banco Hipotecario -. In "Revista Juridica" - vol. 21 - pag. 5 . i 93 .

O caso dos poveiros - In "Revista Juridica" - vol. 20 - pag. 
A sociedade das nações - In "Revista Juridica" - vol. 11 -. pag. 385 .

Reflexões sôbre o conceito da Historia - In "Revista do Instituto Historico e Geografico Brasileiro" — vol. 69 - 2." parte pag. 195.

Elogio de Lucio de Mendonça - In "Revista Americana" tomo 4 - pag. 261.

Interpretação do art. 11 n. 2 e do art. 72 \$\$ 3 e 7 da Constituição Federal - - In-"Revista da Faculdade de Direito de S. Paulo" - vol. 10 - pag. 137.

Succinta exposição historica das leis e decretos que organisaram e têm reformado a Faculdade de Direilo de S. Paulo - Iden vol. 5 pag. 172 . 